\title{
Predictive Model of Rainfall-Runoff: A Case Study of the Sanaga Basin at Bamendjin Watershed in Cameroon
}

\author{
Terence Kibula Lukong (Corresponding author) \\ Hydrology Division, AES SONEL Douala, P.O. Box 433, Douala, Cameroon
}

$\&$

Department of Mathematics and Computer Sciences, Faculty of Science University of Yaounde I

P.O. Box 812, Cameroon

Tel: 237-7477-8879 E-mail:terencelukong@yahoo.com

Michel Mbessa

National Advanced School of Engineering University of Yaounde I

P.O. Box 8390, Yaounde, Cameroon

Tel: 237-7786-3328Ｅ-mail:michel.mbessa@yahoo.fr

\author{
Thomas Tamo Tatietse \\ National Advanced School of Engineering University of Yaounde I \\ P.O. Box 8390, Yaounde, Cameroon
}

Tel: 237-2203-3426Ｅ-mail: thom2t@yahoo.fr

\author{
Received: September 14, $2011 \quad$ Accepted: October 8, $2011 \quad$ Published: December 31, 2011 \\ doi:10.5539/eer.v1n1p193 URL: http://dx.doi.org/10.5539/eer.v1n1p193
}

\begin{abstract}
In order to reduce the energy deficit recorded in Cameroon, management of watersheds where storage dams are situated plays a vital role. The Bamendjin dam situated upstream of the river Sanaga in Cameroon plays a significant role in regulating the flow of the river Sanaga which is used to generate hydroelectric energy for the South Interconnected Network (SIN) of AES SONEL (the main producer and distributor of electricity in Cameroon) at the power plants of Edea and Songloulou downstream of the Sanaga in Cameroon. This paper proposes a model of the watershed that gives an accurate estimation of the quantity of water that will enter the dam given an estimated future rainfall. The model captures the relationships between rainfall and streamflow and to reliably estimate initial watershed states. While future runoff are mainly dependent on initial watershed states and future rainfall, use of the rainfall-runoff models together with estimated future rainfall can produce skillful forecasts of future runoff which is the basis of this prediction system. The result we obtained is a simulated discharge or hydrograph at the outlet (entrance of the dam). To validate it, a comparison of the simulated flowrate and the observed flowrate is carryout using historic data with the Nash Sutcliffe Efficiency Criterion and we obtained an efficiency of 0.833 , meaning that the simulation was good.
\end{abstract}

Keywords: Hydrograph, Flowrate, Model, Watershed
Abbreviations
AES SONEL: AppliedEnergy Services - Société Nationale d'Électricité.
DEM: Digital Elevation Model.
HEC-HMS: Hydrologic Engineering Center-Hydrologic Modeling Systems.
HEC-DSS VUE: Hydrologic Engineering Center-Data Storage System Visual Utility Engine.
GEOSFM: Geospatial Stream Flow Model.
GIS: Geographic Information Systems. 
SIN: South Interconnected Network

\section{Introduction}

Due to rapid computer technology development, mathematical representation of rainfall-runoff has become an important instrument for the hydrologist and water managers, whether for hydrology forecast or for hydroelectric energy generation. The objective is to gain a better understanding of hydrologic behaviors of the watershed and of how changes in the watershed may affect these behaviors thus the generation of synthetic hydrologic data for facility design like water resources planning, and for forecasting. The use of such models in general is preferred due to the limitations of the techniques used in measuring and observing the various components of hydrological systems (Baxter, E.V., 2005).

Hydroelectric Energy is generated based on consumption (demand). In the production of hydroelectric power the formula below gives a representation of the different aspects involved.

$$
P=8 * Q\left(m^{3} / s\right) * H(m)
$$

Where $\mathrm{Q}$ is turbinedflowrate and $\mathrm{H}$ is the height of fall. $\mathrm{Q}$ is directly proportional to power and since the ideal is to maximize (P) power, this relation between power and flowrate shows the importance of flowrate in hydroelectricity generation.

The Sanaga basin which is the largest in Cameroon is exploited for the generation of hydroelectric power equipped with two Power plants downstream of the river Sanaga at Songloulou and Edea which both generate approximately $648 \mathrm{MW}$ of hydroelectricity which is insufficient to satisfy demand for the SIN. To satisfy demand, AES SONEL uses thermal plants (Heavy and Light Fuel) which are very expensive to run to generate more electric energy. The ideal will be to maximize hydroelectric power generation by maximizing the flowrate so as to reduce expenses incurred in running the thermal plants.

The river Sanaga varies in its natural flow considerably due to seasonal variation in Cameroon and records a very

big difference in flowrate during the two seasons (from $8000 \frac{\mathrm{m}^{3}}{\mathrm{~s}}$ to $250 \frac{\mathrm{m}^{3}}{\mathrm{~s}}$ ). Consequently, to manage the Sanaga

basin for optimal hydroelectric power generation to satisfy demand, the Cameroon government has constructed three storage dams on the tributaries of the Sanaga River among which is the Bamendjin dam to regulate the flowrate mainly in the dry season where the decrease of flowrate is alarming. Furthermore, to keep the flowrate maximum during the dry season, proper management of the discharges from the storage reservoirs to make up the flowrate is necessary. Water released from the Bamendjin dam travels 5 days to arrive at the power plants so an accurate forecast of the amount of water that enters the dams (the Bamendjin dam particularly) will help in decision making on proportionate discharges to the power plant. Therefore the model has as objective to give an accurate estimate of the runoff into the Bamendjin dam giving a forecasted rainfall in the basin.

\section{Method and Materials}

Underthe context in consideration, we are going to present a clear and concise explanation of the procedure followed in the development of this model. To develop the rainfall-runoff relationship, information on the watershed needs to be collected, such as: Soil types and infiltration rates, Land use characteristics and the percent of impervious area due to development, Physical characteristics of the watershed including lengths and slopes, Local precipitation patterns. Drainage patterns of the study area, Drainage channel geometry and conditions (U.S Army Corps of Engineers Hydrological Engineering Center, 2009). This information serves as input data and as boundary conditions to the model. Obtain a simulated flowrate for a specific time span that is 1985 \& 1988. We proceed to compare the simulated flowrate with the Observed flowrate within the same time span and optimized model by calibration then obtain a calibration efficiency using the Nash-Sutcliffe model efficiency coefficient (Nash, J. E. and J. V. Sutcliffe, 1970) then we validate model using the split-sample test.

\subsection{Delineation of the subbasin}

The delineation of the subbasin is done using spatial datasets obtained by remote sensing techniques from the United States Geological Survey where we obtained the landcover dataset and from the Food and Agricultural Organization where we obtained the soiltype dataset for the world and the DEM taken at a resolution of $1 \mathrm{~km} *$ $1 \mathrm{~km}$ (Baxter, E.V., 2005). The entire basins of Africa file another spatial dataset is imported into ArcView3.2a where the watershed is situated and delineated by digitalization. The delineated watershed, the DEM, Landcover, 
Soiltype (Zobler, L., 1986), and African basin streams spatial datasets were superimposed in an extension of Arcview3.2a known as the GEOSFM to generate some parameters needed as inputs into the model. These parameters serve as the initial conditions for the model. We called this output the GIS data base (refer to Table $8)$.

\subsection{Model elaboration}

The model HEC-HMS is a numerical model which we use to develop the rainfall-runoff relationship. It is made up of three main components: basin model, meteorologic and control specifications.

\subsubsection{The basin model}

The physical representation of a watershed is accomplished with a basin model. That of our watershed was delineated in GIS software known as ArcView3.2a and imported into HEC HMS. The watershed covers a surface area of $2190 \mathrm{~km}^{2}$ (Dubreuil, P., et al, 1975).The Subbasin element conceptually represents infiltration, surface runoff, and subsurface processes interacting together. Hydrologic elements are connected in a dendritic network to simulate runoff processes. Available elements are: subbasin, reach, junction, reservoir, diversion, source, and sink. Each element represents part of the total response of the watershed to atmospheric forcing and uses a mathematical model to describe the physical process. The Computation of runoff proceeds from upstream elements in a downstream direction. In the delineation, we realized three subbasins for the watershed. Also, a subbasinis an element that usually has no inflow and only one outflow. It is one of only two ways to produce flow in the basin model. Outflow is computed from meteorologic data by subtracting losses, transforming excess precipitation, and adding baseflow. Figure 1 shows the Delineated watershed.

The actual infiltration calculations are performed by a loss method contained within the subbasin. The method permits us to compute runoff volume by computing the volume of water that is intercepted, infiltrated, stored, evaporated, or transpired and subtracting it from the precipitation. Interception, infiltration, storage, evaporation, and transpiration collectively are referred to in this paper as losses. The Green and Ampt infiltration method which is essentially a simplification of the comprehensive Richard's equation for unsteady water flow in soil is used for basin 1 and 2 . The basic equation is given below

$$
f_{t}=K\left[\frac{1+\left(\varnothing-\theta_{i}\right) S_{f}}{F_{t}}\right]
$$

In which $f_{t}=$ loss during period $t ; K=$ saturated hydraulic conductivity; $\left(\varnothing-\theta_{i}\right)=$ volume moisture deficit; $S_{f}=$ wetting front suction; and $F_{t}=$ cumulative loss at time $t$. the table referred to asTable 1 , shows the values of these parameters most of which we got from the Table 7 and the others by calibration.

We chose this method because of availability of data and because during simulation trials it was the most stable for our watershed. The Soil Conservation Service (Now the Natural Resource Conservation Service) curve number method is used for subbasin 3; it implements the curve number methodology for incremental losses and estimates precipitation excess as a function of cumulative precipitation, soil cover, landuse, and antecedent moisture, using the following equation:

$$
P_{e}=\frac{\left(P-I_{a}\right)^{2}}{P-I_{a}+S}
$$

Where $P_{e}=$ accumulated precipitation excess at time $\mathrm{t} ; \mathrm{P}=$ accumulated rainfall depth at time $\mathrm{t} ; \mathrm{Ia}=$ the initial abstraction (initial loss); and $\mathrm{S}=$ potential maximum retention, a measure of the ability of a watershed to abstract and retain storm precipitation.

The choice of SCS curve number as a loss method for subbasin 3 in this watershed is based primarily on the availability of data and also calibration trials showed that the results were more accurate thus the method is simple, predictable, and stable to model losses.(refer to Table 2 for the entries we obtained).

While a basin element conceptually represents infiltration, surface runoff, and subsurface processes interacting together. The actual surface runoff calculations are performed by a transform method contained within the subbasin. The Clark unit hydrograph is a synthetic unit hydrograph method; it is used to model surface runoff for all the three subbasins of our watershed.

There exist a time versus area curve built into the program that is used to develop the translation hydrograph resulting from a burst of precipitation. The resulting translation hydrograph is routed through a linear reservoir to account for storage attenuation affects across the subbasin. The time of concentration defines the maximum travel time in the subbasin. It is used in the development of the translation hydrograph. 
The actual subsurface or baseflow calculations are performed by this method contained within the subbasin. The nonlinear Boussinesqbaseflow method is used. It is designed to approximate the typical behavior observed in watersheds when channel flow recedes after an event. See Table 4 for the values.

The channel flow also referred to as routing models computes a downstream hydrograph, given an upstream hydrograph as a boundary condition; it does so by solving the continuity and momentum equations known as the St Venant's Equation.In HEC-HMS, the various approximations of the continuity and momentum equations are solved using the finite difference method (U.S Army Corps of Engineers Hydrological Engineering Center, 2008).

The Muskingum routing method uses a simple conservation of mass approach to route flow through the stream reach. However, it does not assume that the water surface is level. By assuming a linear, but non-level, water surface it is possible to account for increased storage during the rising side of a flood wave and decreased storage during the falling side. By adding a travel time for the reach and a weighting between the influence of inflow and outflow, it is possible to approximate attenuation. The values here are obtained by calibration.

Loss/gain method: while a reach element conceptually represents a segment of stream or river, optional modelings of interactions with the subsurface are performed by a loss/gain method contained within the reach. A loss/gain method represents losses from the channel, additions to the channel from groundwater, or bi-directional water movements depending on the specific implementation of a method. The constant loss/gain method uses an empirical relationship to calculate channel loss using a fixed flow rate reduction and a ratio of the flow.

\subsubsection{The meteorologic model}

The meteorologic model is responsible for preparing the boundary conditions that act on the watershed during a simulation. Consequently, a meteorologic model is prepared for all basin models. It specifies how precipitation will be generated for each subbasin. The gage weights method particularly arithmetic mean method is used to calculate a Mean Areal Precipitation (MAP). Since the existing rain gauge stations with available historic data in the watershed are insufficient to give a good MAP (we are provided with just four stations: Jakiri, Koundja, Bamenda and Bamendjin). This is a serious problem in Cameroon where we have insufficient hydro-climatological data consequently; it affects the results of our simulation. To model evapotranspiration, the monthly average method was used.

\subsubsection{Data importation into HEC-HMS}

There are three different types of regular time series data that we entered into the model:

\section{Discharge Gages}

The Observed Stream Flow data is entered here as a component of the Discharge gages. The observed stream flow data of NOUN (into the lake of Bamendjin) is entered into the HEC-HMS. This data is obtained from AES-SONEL Database for the period of 1985, 1988 and 1989. The data is obtained in Excel format and needs to follow a precise format in order to be imported into HEC-HMS. The software HEC-DSS VUE 2.0.1 (HEC-DSS Visual Utility Engine) is a graphical user interface program for viewing, editing, and manipulating data in HEC-DSS database files which is used to convert data into .dss format recognized by HEC-HMS.

\section{Precipitation Gages}

We are provided with four raingauge stations mentioned earlier by AES SONEL with the same time interval of observed historic precipitation data for the years 1985, 1988 and 1989. The software HEC-DSS VUE is used to convert the data from the Microsoft Excel format to the format recognized by HEC-HMS.

\section{Evapotranspiration Data}

Evaporation data was obtained only for the station of Bamenda. As a result of the insufficiency and poor estimation of evaporation data for the entire watershed, during the simulation process, we considered just the period from March to December where evapotranspiration is minimal in Cameroon since the peak of the dry season in Cameroon is from January to February where evapotranspiration is maximum, in order to have an acceptable result. We used the Thornthwaite formula to calculate evapotranspiration that transforms evaporation data to evapotranspiration data. A rough estimate of mean areal evapotranspiration was obtained for the basin. The monthly average method was used where data are typically presented as the average depth of evaporated water each month to represent evapotranspiration.

\subsubsection{Control specifications}

They are simply the start and end date and the start and end time. In the simulation we considered daily data with the start date March $1^{\text {st }}$ to $31^{\text {st }}$ December with the time interval of one day with a start time of $12 \mathrm{pm}$ and end time of $12 \mathrm{am}$ because of insufficient evaporation data as indicated earlier. 


\subsubsection{Results}

The results obtained are based on the objectives we earlier set to realize the model:

The simulation run is composed of one meteorologic model, one basin model, and one control specifications. Results can be visualized as graphs. Simulation runs were carried for the years 1985 and 1988. These simulation runs had as objective to test the performance of the model. Daily rainfall time series data was obtained for the interval of time indicated above with observed daily stream inflow data for the same period of time was used for the simulation. To validate our model, Split-sample tests which consist of calibration based on one time period with an independent set of data (1985 and 1988) and validation of the performance of the model on another time period (1989) was carried out. The optimized parameters from the simulations carried out for the two years above was used to replace the initial parameters of the model before a simulation was now carryout for the year 1989; a NSEC was calculated that yielded a value of 0.833 .

Calibration uses observed hydro-meteorological data in a systematic search for parameters that yield the best fit of the computed results to the observed runoff. This search is often referred to as optimization. The quantitative measure of the goodness-of-fit between the computed result from the model and the observed flow is called the objective function. The objective function, equally measures the degree of variation between computed and observed hydrographs. We seek to minimize the objective function to get the best fit for the hydrograph. The objective function used is the Sum of squared residuals. Table 7 shows the calibration values. The Nash-Sutcliffe Efficiency Criterion (NSEC) gave an efficiency value of0.833 for 1985,meaning the simulation was good. Equally we carried out a simulation for the year 1988 and we had an NSEC of 0.847 which means also that the simulation was good. Figure 3 illustrates the simulation carry out.

\section{Discussion and Conclusion}

The hydrograph comparison graphs illustrate the computed outflow and observed stream flow at the objective function evaluation location. This allows us to visually compare how well the computed and observed hydrographs match. Vertical lines are drawn to show the start and end of the objective function time window. The degree to which the hydrographs match helps to indicate the quality of the parameter estimation. The results obtained are satisfactory and acceptable but could have been better if better data acquisition techniques were used which based on recommendations made by our research, AES SONEL is currently implementing a digital data collection system which will render data more reliable for future model simulation. The NSEC value of 0.834 as obtained after the simulation for 1989 has led us to conclude that our model is good and so is an acceptable representation of the rainfall-runoff relationship of the river Noun at the Bamendjin watershed and could respond to most of the forecast problems encountered by AES SONEL to carry-out releases from the storage dam of Bamendjin in order to regulate the Sanaga river for maximum hydroelectric power generation at the power plants of Edea and Songloulou for the SIN of hydro energy supply in Cameroon.

\section{References}

Baxter, E. V. (2005). Distributed Hydrologic Modeling Using GIS (2nd ed.). New York: Kluwer Academic Publishers (Chapter 2, pp. 34 \& 51.).

Denis, N., Michel, M., Acka, K., Joseph, V., and Thomas, T. T. (2011). Application of the Dijkstra Algorithm to the Determination of Minimal Loss Paths in Electrical Networks (pp 4). Pioneer Journal of Advances in Applied Mathematics.

Dubreuil, P., Guiscafre, J., Nouvelot, J. F., Olivry, J. C. (1975). Le Bassin de la Rivière Sanaga. Monographies Hydrologiques Orstom, 3, 111-112. Paris.

Nash, J. E. and Sutcliffe, J. V. (1970). River flow forecasting through conceptual models part I-A discussion of principles. Journal of Hydrology, 10 (3), 282-290. http://dx.doi.org/10.1016/0022-1694(70)90255-6

U.S Army Corps of Engineers Hydrological Engineering Center. (2008). HEC-HMS Application Guide, 16-17.

U.S Army Corps of Engineers Hydrological Engineering Center. (2009). Hydrological Modeling System HEC-HMS User's Manual, Version 3.4.

Zobler, L. (1986). A world soil files for global climate modeling. NASA Technical MEMO 87802-1986. [Online] Available:ftp://daac.gsfc.nasa.gov/data/inter_disc/hydrology/soil/ 
Table 1. Parameters entered into for the loss method for subbasin $1 \& 2$

\begin{tabular}{|l|l|l|l|l|l|}
\hline Subbasin & Initial Loss (MM) & Moisture Deficit & $\begin{array}{l}\text { Suction } \\
(\mathrm{MM})\end{array}$ & $\begin{array}{l}\text { Conductivity } \\
(\mathrm{MM} / \mathrm{HR})\end{array}$ & $\begin{array}{l}\text { Impervious } \\
(\%)\end{array}$ \\
\hline Subbasin-1 & 100 & 0.5 & 500 & 100 & 0.0 \\
\hline Subbasin-2 & 20 & 0.6 & 500 & 50 & 0.0 \\
\hline
\end{tabular}

Table 2. Parameters for subbasin-3 loss method obtained from GIS database

\begin{tabular}{|l|l|l|l|}
\hline Subbasin & Initial Abstraction (MM) & Curve Number & Impervious (\%) \\
\hline Subbasin-3 & & 76 & 0.0 \\
\hline
\end{tabular}

Table 3. Entries for the three subbasins for the Transform method

\begin{tabular}{|l|l|l|}
\hline Subbasin & & \\
\hline Subbasin-1 & 100 & 50 \\
\hline Subbasin-2 & 100 & 0.3 \\
\hline Subbasin-3 & 31.373 & 0.5 \\
\hline
\end{tabular}

Table 4. Subbasin parameters for the Baseflow method obtained from GIS database and calibration

\begin{tabular}{|l|l|l|l|l|}
\hline Subbasin & Ratio & Length(M) & Conductivity(MM/HR) & Porosity \\
\hline Subbasin-1 & 0.2 & 29970.6 & 11.98 & 0.475 \\
\hline Subbasin-2 & 0.2 & 23313.8 & 12.12 & 0.475 \\
\hline Subbasin-3 & 0.45370 & 25213.3 & 1.9556 & 0.475 \\
\hline
\end{tabular}

Table 5. Reach Element values

\begin{tabular}{|l|l|l|l|}
\hline Reach & Muskingum K (HR) & Muskingum X & Number of Subreaches \\
\hline Reach-1 & 100 & 0.0 & 1 \\
\hline Reach-2 & 100 & 0.0 & 2 \\
\hline Reach-3 & 100 & 0.0 & 2 \\
\hline
\end{tabular}

Table 6. The values of Constant Loss/Gain parameters obtained by calibration

\begin{tabular}{|l|l|l|}
\hline Reach & Flow Rate $(\mathrm{M} 3 / \mathrm{S})$ & Fraction \\
\hline Reach-1 & 50 & 0.2 \\
\hline Reach-2 & 70 & 0.2 \\
\hline Reach-3 & 50 & 0.2 \\
\hline
\end{tabular}


Table 7. Optimized parametric values after optimization trials were run

\begin{tabular}{|l|l|l|l|l|l|}
\hline Element & Parameter & Units & $\begin{array}{l}\text { Initial } \\
\text { Value }\end{array}$ & $\begin{array}{l}\text { Optimized } \\
\text { Value }\end{array}$ & $\begin{array}{l}\text { Objective } \\
\text { Sensitivity }\end{array}$ \\
\hline $\begin{array}{l}\text { ALL } \\
\text { Subbasins }\end{array}$ & Hydraulic conductivity & & 1.00 & 1.00000 & 0.00 \\
\hline Subbasin-3 & $\begin{array}{l}\text { Clark Time of } \\
\text { concentration }\end{array}$ & HR & 75 & 18.157 & 0.00 \\
\hline Subbasin-1 & $\begin{array}{l}\text { Clark Time of } \\
\text { concentration }\end{array}$ & HR & 100 & 100.000 & 0.00 \\
\hline Reach-2 & Muskingum K & HR & 102.01 & 110.48 & 0.00 \\
\hline All Subbasins & Initial Loss scale Factor & & 1.0 & 1.000000000 & 0.00 \\
\hline All Subbasins & Moisture Deficit Scale & & 1.0 & 1.0000000 & 0.00 \\
\hline All Subbasins & Wetting Front Suction & & 1.0 & 1.000000 & 0.00 \\
\hline Subbasin-3 & BaseFlow & & 3 & $3-2480$ & 0.00 \\
\hline Reach-3 & Muskingum K & & 100 & 11.650 & -0.01 \\
\hline Reach-3 & Number of Steps & & 2 & 2 & \\
\hline Subbasin-3 & Baseflow Threshold & & 0.2 & 0.46324 & -0.13 \\
\hline
\end{tabular}

Table 8. GIS database (River and Basin characteristics generated from ArcView3.2a)

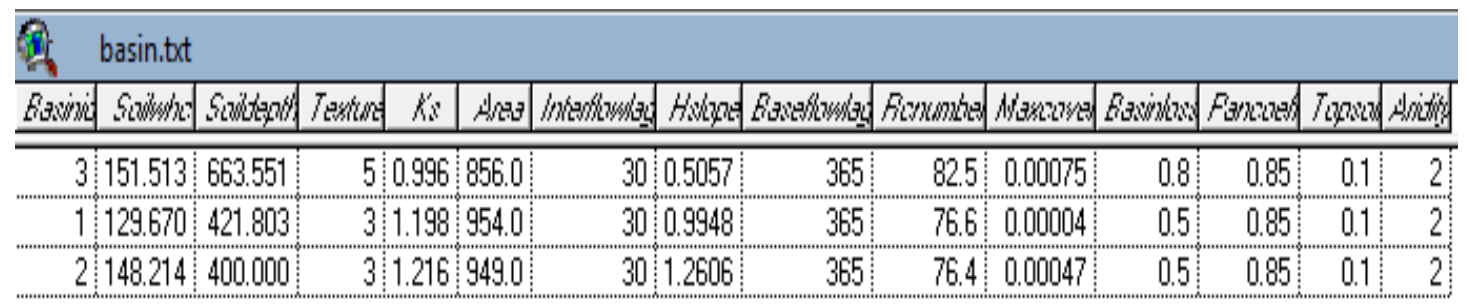

\section{river.toxt}

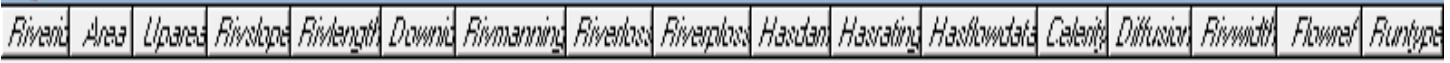

\begin{tabular}{|c|c|c|c|c|c|c|c|c|c|c|c|c|c|}
\hline 3856.0 & 2755.0 & 0.0238 & 25213.2 & 0 & 0.035 & 1.0 & 1.0 & 0 & 0 & 0 & 0.3 & $1134.695 .7597 \quad 52.6543$ & 0 \\
\hline 1954.0 & 953.0 & 0.3670 & 29970.6 & 3 & 0.035 & 1.0 & 1.0 & 0 & 0 & 0 & 0.8 & $3596.566 .2530: 56.6820$ & 0 \\
\hline 29490 & 945.0 & 0.4504 & 23313.7 & 3 & 0.035 & 1.0 & 1.0 & 0 & 0 & 0 & 1.0 & $3497.1 \quad 66.0595566 .4798$ & \\
\hline
\end{tabular}




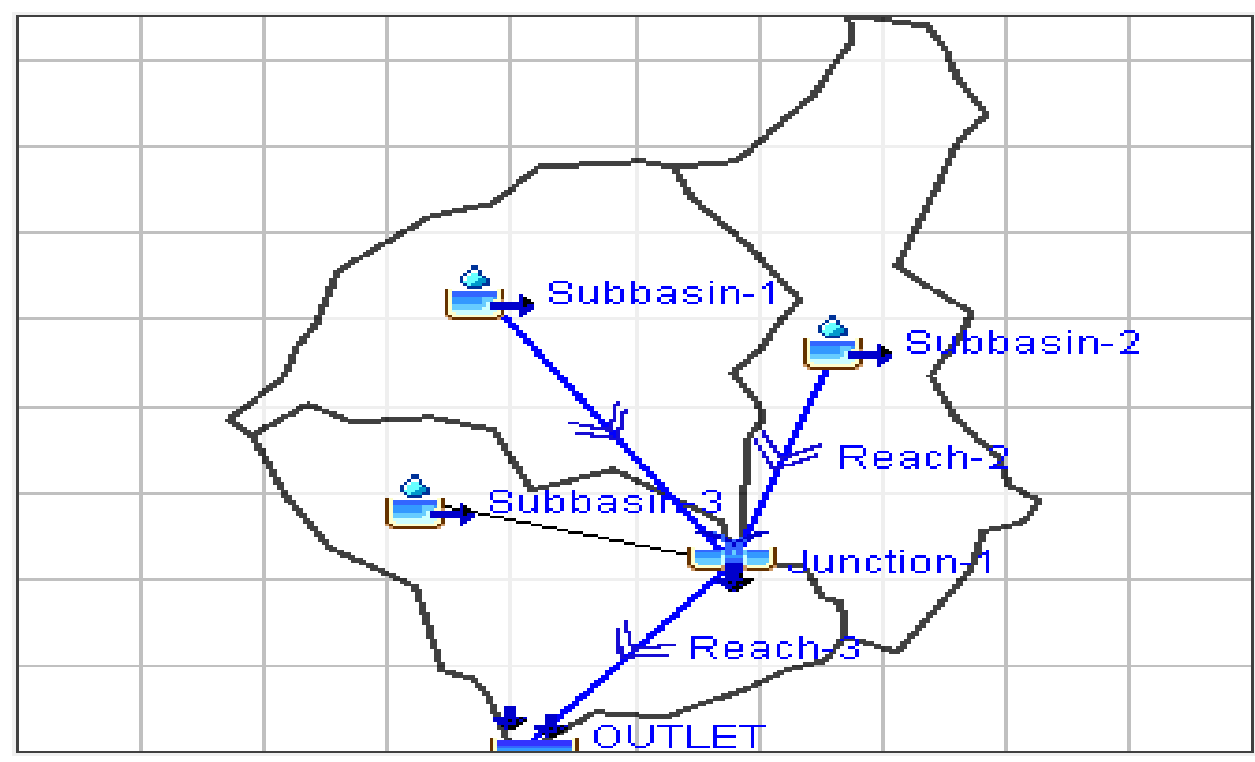

Figure 1. Delineated watershed of Noun at Bamendjin with the hydrographic network

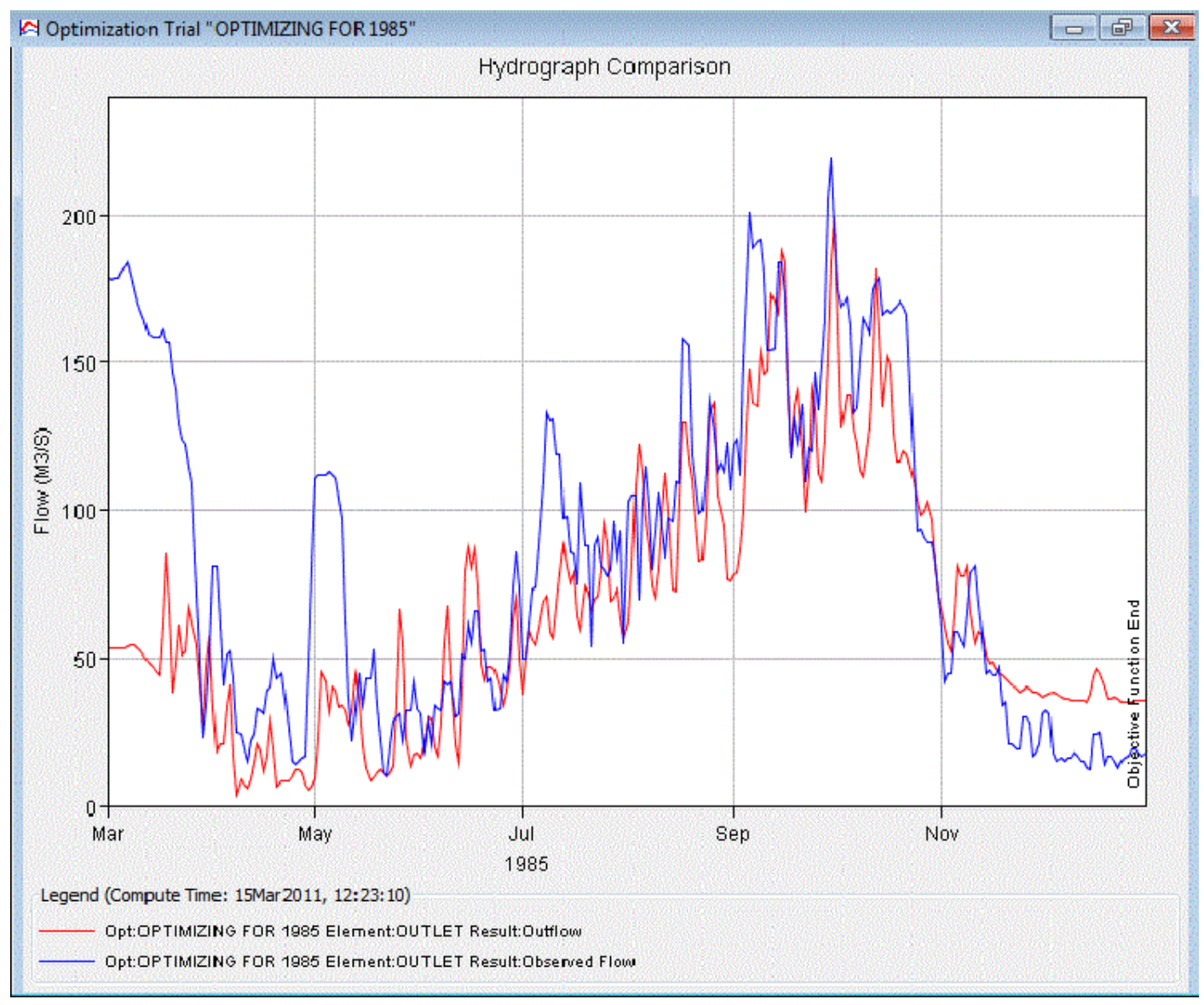

Figure 2. Optimized Hydrograph Comparison red for simulated flow and blue for observed streamflow for 1985 


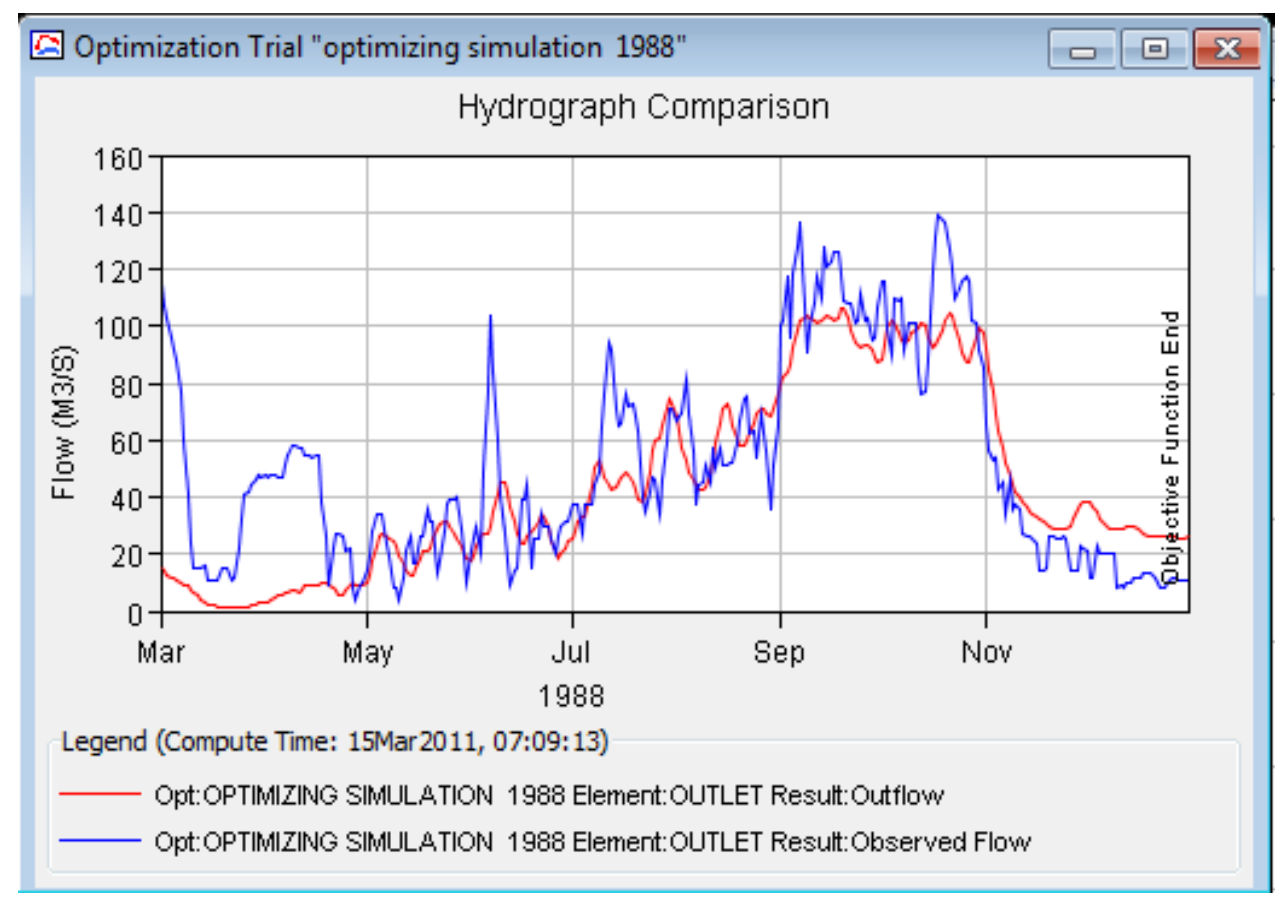

Figure 3. Optimized Hydrograph Comparison red for simulated flow and blue for observed streamflow for 1988

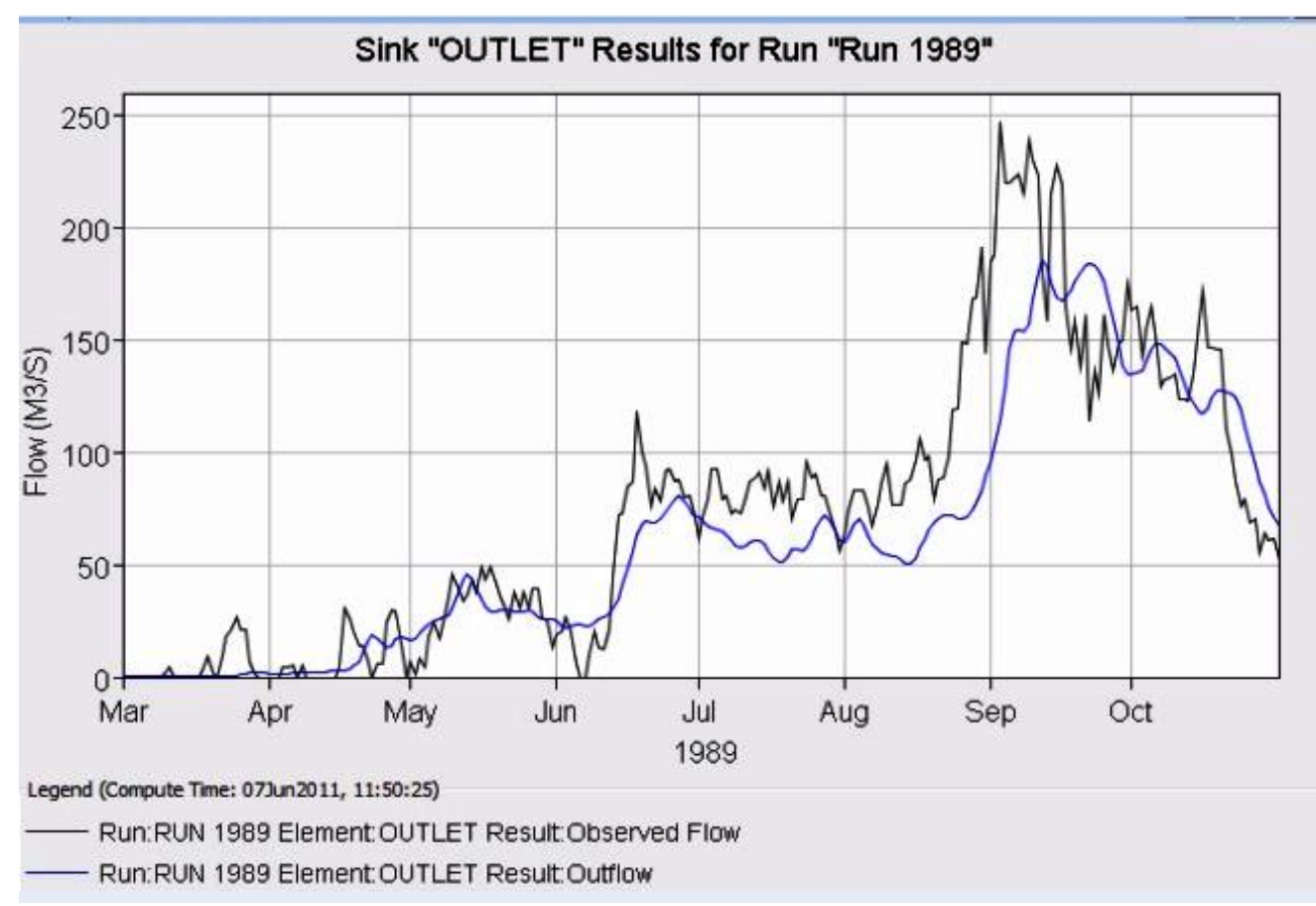

Figure 4. Optimized Hydrograph Comparison red for simulated flow and blue for observed streamflow for 1989 